\title{
Weight Determination of Sustainable Development Indicators Using a Global Sensitivity Analysis Method
}

\author{
Wenfei Luan ${ }^{1,2}$, Ling $\mathrm{Lu}^{1,4}$, Xin $\mathrm{Li}^{1,3}$ and Chunfeng Ma ${ }^{1, *}$ \\ 1 Key Laboratory of Remote Sensing of Gansu Province, Northwest Institute of Eco-Environment and \\ Resources, Chinese Academy of Sciences, Lanzhou 730000, China; luanwf@lzb.ac.cn (W.L.); \\ luling@lzb.ac.cn (L.L.); lixin@lzb.ac.cn (X.L.) \\ 2 University of Chinese Academy Sciences, Beijing 100049, China \\ 3 CAS Center for Excellence in Tibetan Plateau Earth Sciences, Beijing 100049, China \\ 4 Key Laboratory of Inland River Basin Eco hydrology, Northwest Institute of Eco-Environment and \\ Resources, Chinese Academy of Sciences, Lanzhou 730000, China \\ * Correspondence: machf@lzb.ac.cn; Tel.: +86-931-496-7236 \\ Academic Editor: Guangwei Huang \\ Received: 28 November 2016; Accepted: 13 February 2017; Published: 21 February 2017
}

\begin{abstract}
Sustainable development (SD) evaluations have attracted considerable attention from governments and scientific communities around the world. The objective and quantitative calculation of the importance of sustainable assessment indicators is a key problem in the accurate evaluation of SD. Traditional methods fail to quantify the coupling effects among indicators. This paper presents a weight determination approach based on the global sensitivity analysis algorithm known as the extended Fourier amplitude sensitivity test (EFAST). This method is efficient and robust and is not only able to quantify the sensitivity of the evaluation indictors to the target, but can also quantitatively describe the uncertainties among the indictors. In this paper, we analyze the sensitivity of 18 indicators in a multi-index comprehensive evaluation model and weigh the indicators in the system according to their importance. To verify the feasibility and advantages of this new method, we compare the evaluation result with the traditional entropy method. The comparison shows that the EFAST algorithm can provide greater detail in an SD evaluation. Additionally, the EFAST algorithm is more specific in terms of quantitative analysis and comprehensive aspects and can more effectively distinguish the importance of indicators.
\end{abstract}

Keywords: weight determination; EFAST algorithm; agriculture sustainable development; entropy method; global sensitivity analysis

\section{Introduction}

Sustainable development (SD) has become a major criterion in the evaluation of the degree of healthy development in a region or country. Quantitatively measuring the state of SD has become an important aspect of SD research [1,2]. The premise and foundation of realizing SD is the identification of the present situation, and the core of this work involves quantitatively and accurately evaluating the present SD level using a reasonable weight determination method for each evaluation indicator [3].

Many researchers have quantitatively evaluated the present SD level using traditional weight determination methods. Si et al. [4] evaluated the environmental sustainability of coal mining in the Qijiang area with the analytic hierarchy process (AHP) method, in which they determined indicator weights through pairwise comparisons. However, this method relies on the judgements of decision-makers to derive the priority scales. Karger et al. [5] evaluated the sustainability of decentralized electricity generation using the AHP and expert judgement method and determined the weight of each indicator by quantifying expert expertise via the AHP procedure. However, neither 
of these methods is applicable when the decision-maker is not familiar with the indicator in the evaluation system. Qiao et al. [6] evaluated the SD level of Henan province using the entropy method. This easy-to-use method can obtain the weight based solely on the analysis of data from different years or regions, and human intervention is not required. However, the entropy method does not take the coupling effect among indicators into consideration.

The above studies reflect two main types of weight determination methods, subjective and objective methods. To quantitatively and accurately evaluate the SD level, we must precisely and objectively fix the weights of the indicators [7,8]. However, both types of methods have their inherent shortcomings. The subjective methods (such as the analytic hierarchy process and expert judgement method) are significantly influenced by human knowledge and experience, which affect the objectivity of the results to a certain extent [9]. Objective methods (such as the entropy method) are based completely on data analysis and do not fully consider the coupling effects among indicators, thereby causing deviations in the evaluation results. In recent research, some researchers have combined the previous methods into an integrated method [10-12]. Such an integrated method can determine weight more reasonably by combining human intervention with data analysis. However, all of these methods fail to consider the relationships among indicators. To accurately calculate the SD level, this effect cannot be neglected. Thus, a more comprehensive approach that can quantitatively calculate the uncertainty of the coupling effect among indicators needs to be used.

The extended Fourier amplitude sensitivity test (EFAST) [13] is a quantitative global sensitivity analysis algorithm that can quantify the sensitivity of each indicator to the target and quantitatively describe the relationships among the indicators. Using the EFAST algorithm, we can calculate the main sensitivity index (MSI) and total sensitivity index (TSI). The MSI reflects the influence of a single indicator to the model output, and the TSI (the sum of MSI and coupling effect) represents the entire influence of the indicator on the model output. This method considers the coupling effect among indicators and is more in line with the objective reality.

This paper proposes a new weight determination solution based on the global sensitivity analysis method. The overall objectives are to quantitatively evaluate the indicator sensitivities in the evaluation system and obtain the indicator weights through the sensitivity index (SI, including MSI and TSI) normalization and to provide a deeper understanding of uncertainty among indicators from a quantitative perspective. In this paper, two specific issues are explored: (1) Can we obtain reliable and comprehensive weights for SD indicators via a global sensitivity analysis method? (2) Does our new method exhibit evident advantages when compared with traditional methods? To answer these questions, we do the following work: (1) analyze the sensitivity of each indicator in the selected system and determine the indicator weights on the basis of their SI values; and (2) compare the results to those determined using a traditional entropy method.

The remainder of this paper comprises five sections. The materials, the traditional entropy method and the EFAST method are described in Section 2. The results of this study are described in Section 3. The discussion is provided in Section 4, and our conclusions are presented in Section 5.

\section{Materials and Methods}

\subsection{Overview of the Indicator System}

The focus of research on SD began to turn to the evaluation of the sustainable development level, especially the construction of the indicator system [14], in the 1990s. Many comprehensive indicator systems with great international influence have been proposed. For example, the "pressure-state-response" (PSR) model [15] was proposed by the Organization for Economic Co-operation and Development. The sustainable development indicator system was released by the World Bank, and the Sustainable Development Goals system was proposed by the UN Sustainable Development Summit [16]. All of these systems are complex. Researchers have conducted numerous studies on the evaluation of regional SD levels or on some particular aspects of SD. The China 
agricultural sustainable development and comprehensive productivity research team, for instance, established a comprehensive evaluation system for agricultural SD [17]. Joung et al. [18] proposed a manufacturing SD system. The indicator systems related to regional SD or certain SD aspects were based on regional characteristics or too specific. Consequently, these systems are not universal and cannot be used by all researchers. To simplify the data requirements and the degree of familiarity with certain aspects necessary to perform this research, we use an agriculture SD indicator system as an example in this study. The method we introduce is also suitable for complex indicator systems.

This research adopts China's agricultural sustainable development evaluation indicator system built by Xin [19] (2015) and others. Considering the availability of data and the completeness and representativeness of the indicators, we have changed some of the indicators as follows: the "fertilizer use intensity" indicator has been replaced with "chemical fertilizer application rate assuming 100\% utilization"; "fertilizer utility contribution rate" has been replaced with "chemical fertilizer-dependent output assuming 100\% utilization"; "ecological environmental disaster coefficient" has been replaced with "improvement rate of soil and water loss". Additionally, because the influence of meteorological disasters on agriculture should not be neglected, we have added an "agricultural disaster area" indicator to the system (Table 1).

Table 1. Indicator system for the evaluation of agricultural sustainability development in Henan province.

\begin{tabular}{|c|c|c|}
\hline Number & Index & Computing Method \\
\hline 1 & Net income per capita of farmers (yuan) & $\begin{array}{l}\text { Net income of rural households/rural households } \\
\text { resident population }\end{array}$ \\
\hline 2 & Arable land output level (yuan/hm²) & Agricultural output/arable land \\
\hline 3 & Grain share per capita (kg/person) & Food production/total population \\
\hline 4 & Meat share per capita (kg/person) & Meat production/total population \\
\hline 5 & Fish consumption per capita (kg/person) & Aquatic products/total population \\
\hline 6 & Mechanical effective utilization factor $\left(\mathrm{kw} / \mathrm{hm}^{2}\right)$ & Mechanical power/arable land \\
\hline 7 & Effective irrigation coefficient $(\%)$ & Effective irrigation area/arable land \\
\hline 8 & $\begin{array}{l}\text { Chemical fertilizer-dependent output assuming } 100 \% \\
\text { utilization (yuan } / \mathrm{hm}^{2} \text { ) }\end{array}$ & $\begin{array}{l}\text { Agricultural output/consumption of chemical } \\
\text { fertilizer by } 100 \% \text { effective component }\end{array}$ \\
\hline 9 & Multiple cropping index (\%) & Crop acreage/arable land \\
\hline 10 & Arable land per capita $\left(\mathrm{hm}^{2} /\right.$ person $)$ & Cultivated area/total population \\
\hline 11 & Forest coverage $(\%)$ & Forest area/total land area \\
\hline 12 & Improvement rate of soil and water loss (\%) & $\begin{array}{l}\text { Soil and water loss improvement area/soil and } \\
\text { water loss area }\end{array}$ \\
\hline 13 & $\begin{array}{l}\text { Chemical fertilizer application rate assuming 100\% } \\
\text { utilization }\left(\mathrm{kg} / \mathrm{hm}^{2}\right)\end{array}$ & $\begin{array}{l}\text { Consumption of chemical fertilizer by } 100 \% \\
\text { effective component/crop acreage }\end{array}$ \\
\hline 14 & Agricultural disaster area $\left(1000 \mathrm{hm}^{2}\right)$ & Directly from Henan Statistical Yearbook \\
\hline 15 & Pesticide use intensity $(\mathrm{kg} / \mathrm{hm} 2)$ & Pesticide amount/crop acreage \\
\hline 16 & Plastic sheeting use $\left(\mathrm{kg} / \mathrm{hm}^{2}\right)$ & Plastic sheeting/crop acreage \\
\hline 17 & Agricultural energy consumption index (t/10 4 yuan) & $\begin{array}{l}\text { Agriculture, forestry, animal husbandry and } \\
\text { fishery energy consumption/agricultural output }\end{array}$ \\
\hline 18 & $\begin{array}{l}\text { Water use per } 10^{4} \text { yuan of agricultural output } \\
\left(\mathrm{m}^{3} / 10^{4} \cdot \text { yuan }\right)\end{array}$ & Agricultural water/agricultural output \\
\hline
\end{tabular}

\subsection{Data}

The data (Table 2) adopted in this paper mainly come from the Henan Statistical Yearbook (2000-2009). Additionally, the data for the "water use per $10^{4}$ yuan of agricultural output" indicator are from the Henan Water Resources Bulletin (2000-2009). The "Chemical fertilizer-dependent output assuming $100 \%$ utilization" and "Chemical fertilizer application rate assuming $100 \%$ utilization" data are derived from the New China 60 Years of Statistical Data Collection. 
Table 2. Original data of each indicator in Henan province during 1999-2008.

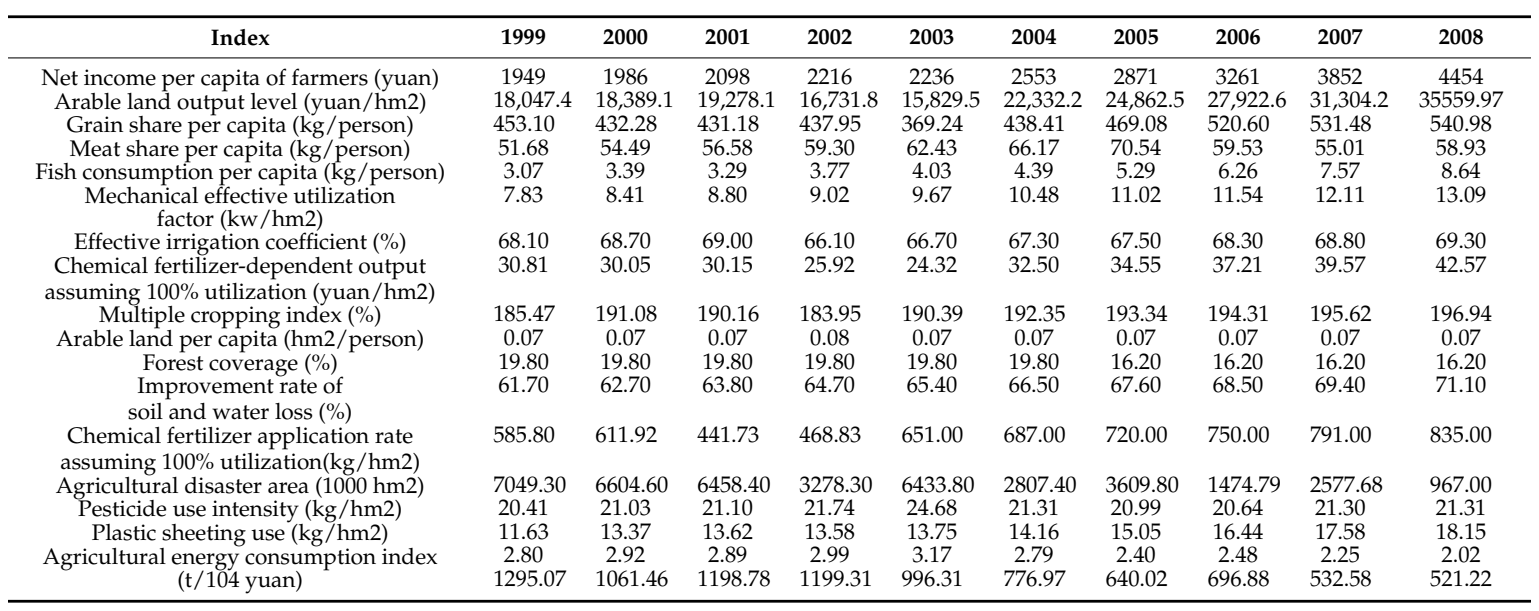

\subsection{Model}

Scholars have proposed many SD evaluation models, and commonly-used methods include the ecological footprint method [20], the data envelope analysis model [21], the multi-index comprehensive analysis model [22], and others. The multi-index comprehensive analysis model has a fixed formula, and using a simple linear weighted sum function, we developed a comprehensive index. Because the results from this simple model are relatively intuitive and clear, it has been used in multiple applications by academics.

This study inputs the Henan Province data from 1999-2008 into the multi-index comprehensive analysis model. Because the raw data have different units and cannot be compared, we need to standardize the original data. Thus, this study adopts the extreme standardization method, using Formula (1) for positive indicators and Formula (2) for negative indicators:

$$
\begin{gathered}
P_{j i}=\frac{x_{j i}-x_{\min }}{x_{\max }-x_{\min }} \\
P_{j i}=\frac{x_{\max }-x_{j i}}{x_{\max }-x_{\min }}
\end{gathered}
$$

where $p_{j i}$ is the standardization of the indicator data; $x_{j i}$ is the original index data for the $i$ th original indicator data in the $j$ th year; $x_{\max }$ is the highest index value over the 10 -year period; and $x_{\min }$ is the lowest index value over the 10-year period.

In this case, we set the multi-index comprehensive evaluation model to the following linear expression:

$$
T_{j}=\sum_{i=1}^{n}\left(w_{j i} \times P_{j i}\right) \times 100
$$

where $T_{j}$ is the comprehensive agricultural sustainable development indicator of the $j$ th year in Henan province, $n$ is the number of indicators and $w_{j i}$ is the weight of the $i$ th indicator in the $j$ th year.

\subsection{Weight Determination Methods}

In this section, the two weight determination methods used in this paper-the EFAST algorithm and the entropy method-will be introduced. The EFAST algorithm is our primary method, and the entropy method is used for validation. Thus, the entropy method is introduced briefly, and the EFAST algorithm is described in more detail. 


\subsubsection{EFAST Algorithm and Its Implementation in Indicator Weighing}

The EFAST algorithm is based on the FAST method and incorporates the advantages of the Sobol [23] method to calculate the TSI. Thus, the method exhibits the efficient sampling of the FAST method and the precise TSI calculation of the Sobol method. As a quantitative global sensitivity analysis algorithm, it has been widely used in parameter sensitivity analyses of ecology, hydrology and remote sensing models [24-28]. EFAST is based on the analysis of variance; thus, the first-order sensitivity index (the main effect, also called the MSI) represents the influence a single parameter on the model output, and the TSI (total effect) represents the influence of both the main effect and the coupling effect among indicators on the model output. The EFAST algorithm calculates the model output result by sampling the input parameters a certain number of times and analyzing the variance associated with each parameter caused by the parameter itself and by the coupling effect, which represents the interactions with other parameters.

A model with $n$ parameters can be written as follows: $y=f\left(x_{1}, x_{2}, \ldots, x_{n}\right)$. According to the variance decomposition method of Sobol, the model output variance can be decomposed into the following components:

$$
V=\sum_{i} V_{i}+\sum_{i \neq j} V_{i j}+\sum_{i \neq j \neq k} V_{i j k}+\ldots+\sum V_{12 \ldots n}
$$

where $V_{i}$ is the variance caused by parameter $x_{i}, V_{i j}$ is the variance caused by the coupling effect associated with parameter $x_{j}$ and $V_{12 \ldots n}$ is the variance caused by the coupling effects associated with parameters $x_{1}, x_{2}, \ldots, x_{n}$. The MSI of parameter $x_{i}$ can be defined as Equation (5):

$$
S_{i}=\frac{V_{i}}{V}
$$

Similarly, the second-order and the third-order sensitivity index of parameter $x_{i}$ can be defined as Equation (6):

$$
S_{i j}=\frac{V_{i j}}{V}, S_{i j k}=\frac{V_{i j k}}{V}
$$

The TSI of parameter $x_{i}$ is the sum of each order of the sensitivity index:

$$
S T_{i}=S_{i}+S_{i j}+S_{i j k}+\ldots S_{12 \ldots n}
$$

The influences of different indicators on the model output vary, and the effect of mutual coupling among the indicators produces certain uncertainties in the evaluation results. Thus, a rational weight determination for indicators is a complicated process. The EFAST algorithm can quantitatively compare the importance of each parameter by changing a single indicator weight to quantitatively analyze the patterns of fluctuation in the target function. Because using an importance ranking to assign weights to the indicators is a rational technique, this method also can help to reduce the effects of misleading information.

The EFAST algorithm is embedded in Simlab2.2 [29] (Simulation Laboratory for Uncertainty and Sensitivity Analysis), a software package published by the European Commission Joint Research Center. This study uses the software for the global sensitivity analysis of each input indicator. Simlab2.2 includes data preprocessing, model calculation and data post-processing modules. In this paper, the indicator weights can be applied as input parameters. The data preprocessing module requires the choice of the probability density distribution function for each indicator weight and the indicator weight range (i.e., between 0 and 1). Because the probability distribution of the weights is unpredictable, it is appropriate to select a uniform distribution function. Considering the computational efficiency and the number of representative samples, the sampling size of each indicator weight is set to 9825 (the EFAST algorithm is thought to be effective when the sampling size is 65-times greater than the number of parameters, and the default sampling size of the software is 9825 when the size is 
set to 10,000). In the research, we obtain the input samples after sampling. A model calculation module can be embedded in both the external and internal models. The multi-index comprehensive evaluation model is a simple linear model; thus, building an internal model in the software is very convenient. In this case, Formula (3) is embedded in the module. A Monte Carlo simulation is then run after model construction. Finally, the sensitivity of the indicators is calculated in the data post-processing module, and the MSI and TSI of each indicator are exported.

The TSI contains the model output variance contributed by both the individual indicator and the coupled indicators. More importantly, the TSI more fully reflects the importance of the indicators for the objective function. To make the weights more comprehensive, we needed to add the coupling effects into the weight determination. Hence, we chose the TSI to act as the basis of the weight determination.

By calculating the TSI of each indicator weight for every year, we can obtain the weight of the $i$ th indicator in the $j$ th year $\left(\omega_{j i}\right)$ after the TSI normalization process.

$$
\omega_{j i}=S T_{i} / \sum_{i=1}^{18} S T_{i}
$$

Equation (9) calculates the final average weight of each indicator for 1999-2008:

$$
\omega_{i}=\frac{\sum_{j=1999}^{2008} \omega_{j i}}{10}
$$

where $\omega_{i}$ is the final weight of the indicator.

\subsubsection{Entropy Method on Weight Determination}

The degree of discreteness of an indicator can be determined by calculating the entropy of the indicator. Discreteness is important because the greater the degree of discreteness is, the greater the influence of the indicator on the comprehensive evaluation. The use of the entropy method to fix the weight includes the following steps:

First, the original data matrix $X=\left(x_{j i}\right)_{m \times n^{n}}$, where $m$ is the year and $n$ is the number of indicators, is established. Second, standardization processing is applied to the original data using Formulas (1) and (2). Then, the normalization process is used to obtain the standard matrix $Y=\left(y_{j i}\right)_{m \times n^{\prime}}$

$$
y_{j i}=p_{j i} / \sum_{j=1}^{m} p_{j i}
$$

Next, the entropy $e_{i}$ and redundancy $d_{i}$ of indicator $i$ are calculated:

$$
e_{i}=-K \sum_{j=1}^{m} p_{j i} \ln p_{j i}
$$

where $K=1 / \ln n$ and redundancy $d_{i}=1-e_{i}$.

Finally, the weight $\omega_{i}$ of indicator $i$ is calculated.

$$
\omega_{i}=d_{i} / \sum_{i=1}^{n} d_{i}
$$

The entropy method fixes the weights by analyzing the degree of discreteness of the indicators, and the whole process depends entirely on data analysis. 


\subsubsection{Brief Comparison of the EFAST Method and Entropy Method}

Both the EFAST method and the entropy method are objective methods. Compared with the subjective method, the objective method avoids the influence of evaluators calling upon their professional knowledge and experience. Therefore, the objective method has been extensively used. The entropy method is a mature method and widely used because of its agility and practicality. Besides, it is an easily-operated method and can be applied without any background knowledge. Better yet, the EFAST can quantitatively calculate the coupling effect among indicators. Taking the coupling effect into consideration is a more comprehensive idea when fixing weights for the indicators. Although the EFAST is widely used in many research fields, it has not been applied in weight determination. Additionally, the calculating process of EFAST method is slightly more complicated than the entropy method.

\section{Results}

\subsection{Sensitive Analysis of Indicators in Different Stages}

As shown in Figure 1, the MSI of each indicator is slightly less than the TSI. The red bars show the effects of indicator interaction and suggest that a certain degree of coupling exists among the indicators. The value of the coupling effect is calculated to be within a range of $0.002-0.005$. Although the effect is small, it cannot be neglected when accurately calculating the degree of influence of the indicator on the model output. Therefore, the TSI of each indicator in different stages is specifically analyzed.

Between 1999 and 2003, the TSI is greater than 0.06, and the indicators include arable land per capita, forest coverage, chemical fertilizer application rate assuming $100 \%$ utilization and plastic sheeting use. The total averaged sensitivity index values of these four indicators during this period were $0.1038,0.2574,0.1586$ and 0.1594 , respectively. The sum of their values is 0.6792 , which is much higher than that of the other 14 indicators. Cultivatable land is the basic requirement for the development of agriculture, and per capita arable land is the estimate of agricultural production. Hence, the high TSI value of this parameter agrees with reality. Forest coverage plays an important role in water and soil conservation and in the improvement of the ecological environment, and this parameter is highly sensitive when coupled with other indicators. The other two indicators belong to agricultural input resources. These results indicate that farmers during this period attached great importance to agricultural input. During the 2004-2008 period, the differences among the TSI values are reduced. In 2006-2008, the TSI values of net income per capita of farmers, arable land output level, fish consumption per capita, chemical fertilizer-dependent output assuming $100 \%$ utilization (yuan $/ \mathrm{hm}^{2}$ ), multiple cropping index, Improvement rate of soil and water loss, water use per $10^{4}$ yuan of agricultural output are greater than 0.06 and the sum of their values is 0.734 . The values range from $0.066-0.151$, with most concentrated near 0.08 . The differences among the TSI values in a given year are lower than those in the 1999-2003 period. The attention paid to a greater number of indicators indicates that the agricultural development sustainability efforts were more comprehensive during this period. 

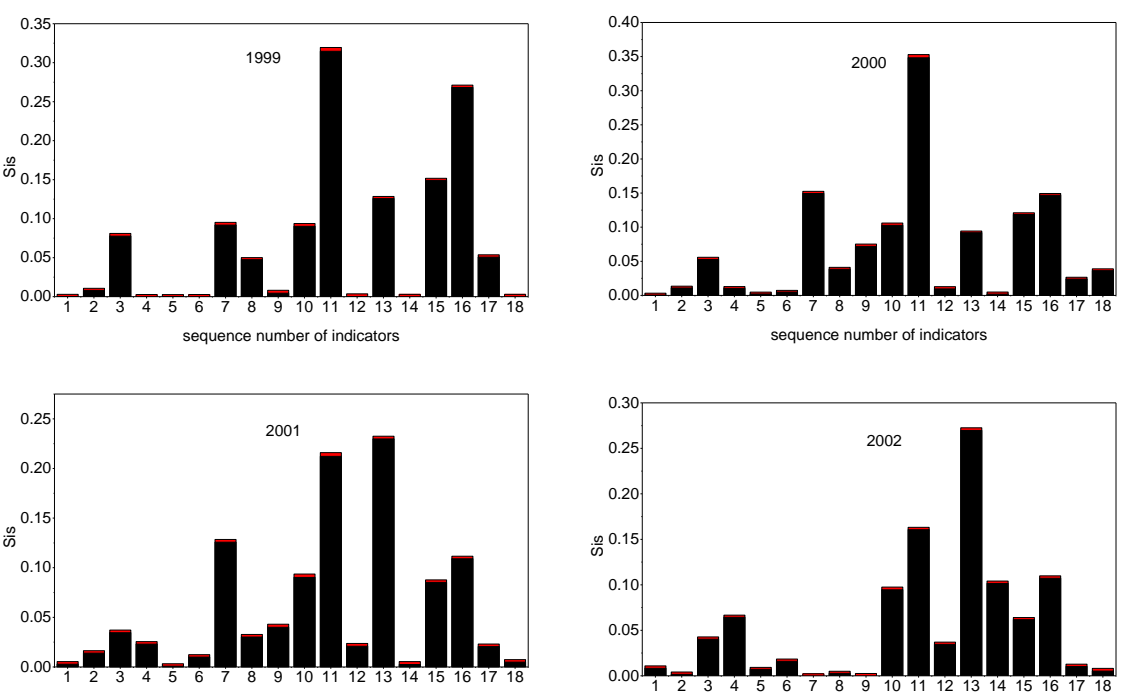

sequence number of indicators
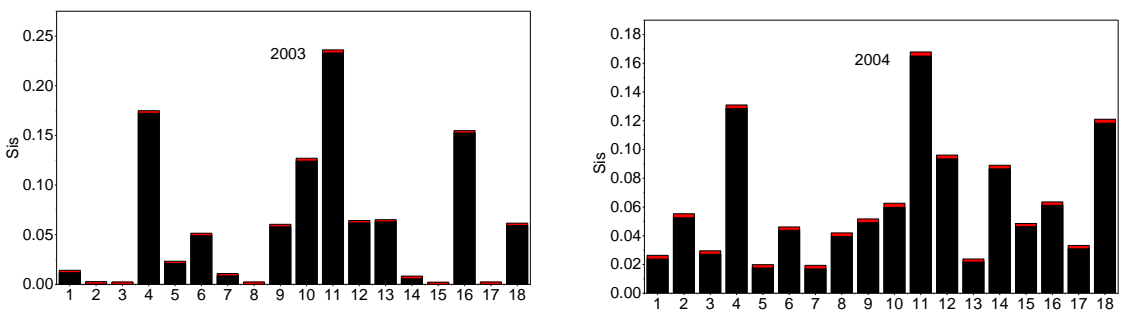

sequence number of indicators

sequence number of indicators
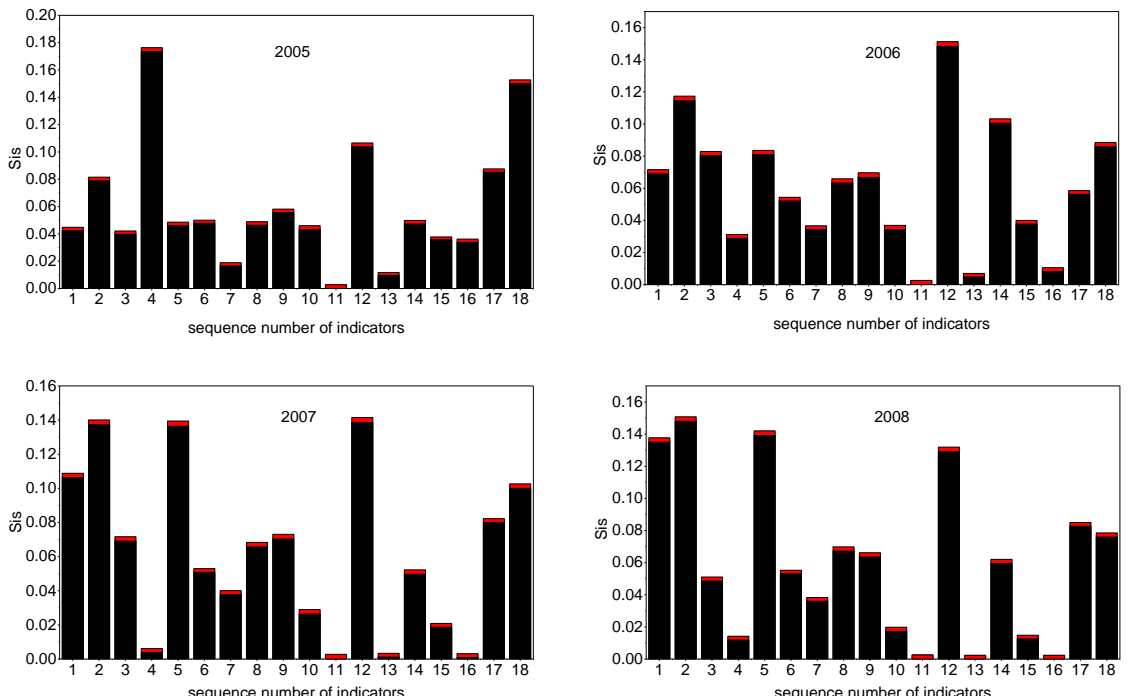

Figure 1. Sensitivity index value of each indicator. Legend: 1. Net income per capita of farmer (yuan/person). 2. Arable land output level (yuan $/ \mathrm{hm}^{2}$ ). 3. Grain share per capita (kg/person). 4. Meat share per capita (kg/person). 5. Fish consumption per capita (kg/person). 6. Mechanical effective utilization factor $\left(\mathrm{kw} / \mathrm{hm}^{2}\right)$. 7. Effective irrigation coefficient (\%). 8. Chemical fertilizer-dependent output assuming $100 \%$ utilization (yuan $/ \mathrm{hm}^{2}$ ). 9. Multiple cropping index (\%). 10. Arable land per capita ( $\mathrm{hm}^{2} /$ person). 11. Forest coverage (\%). 12. Improvement rate of soil and water loss (\%). 13. Chemical fertilizer application rate assuming $100 \%$ utilization $\left(\mathrm{kg} / \mathrm{hm}^{2}\right)$. 14. Agricultural disaster area $\left(1000 \mathrm{hm}^{2}\right)$. 15. Pesticide use intensity $\left(\mathrm{kg} / \mathrm{hm}^{2}\right)$. 16. Plastic sheeting use $\left(\mathrm{kg} / \mathrm{hm}^{2}\right)$. 17. Agricultural energy consumption index ( $\mathrm{t} / 10^{4}$ yuan). 18. Water use per $10^{4}$ yuan of agricultural output $\left(\mathrm{m}^{3} / 10^{4}\right.$ yuan). 


\subsection{Analysis of the Weights Determined by the EFAST Algorithm}

Based on the results of the sensitivity analysis of EFAST, we can easily obtain the weights determined by the EFAST. Figure 2 shows the comparison of indicators' weights determined by EFAST and entropy, respectively. Here, we only analyze the weights fixed by the EFAST method. The differences between these two methods will be discussed in the next section. The top five indicators in the EFAST method, representing a total proportion of $41.1 \%$, are forest coverage, chemical fertilizer application rate assuming $100 \%$ utilization, improvement rate of soil and water loss and arable land per capita, and the weights are $0.126,0.078,0.075,0.078$ and 0.075 , respectively. These top five indicators include the ecology, resources and environment indicators. These five indicators fully reflect that on which we focus. Additionally, the weights of the remaining indicators are between 0.015 and 0.06 , which might have a weak influence on the evaluation result. By comparing with the results obtained by the entropy method, which has been commonly recognized [30-32], we show that the two methods exhibit high similarities. Thus, we can conclude that the EFAST algorithm is able to effectively recognize the importance of the indicators.

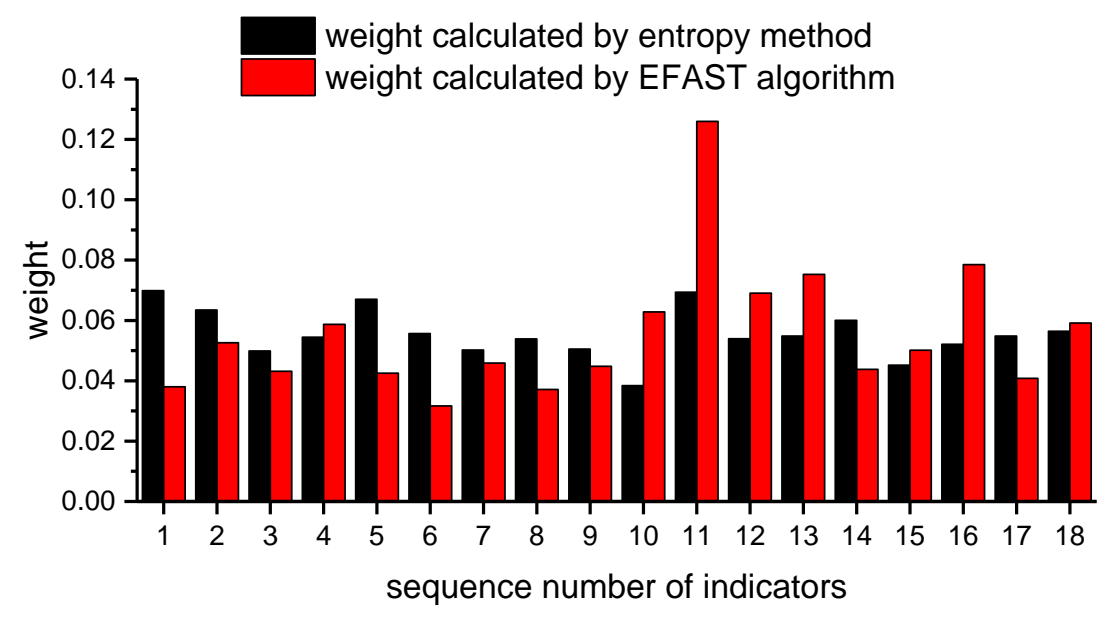

Figure 2. Weights calculated by the entropy method and the EFAST algorithm (Legend: same as in the previous figure).

\section{Discussion}

\subsection{Comparison of the Weights Determined by the EFAST Algorithm and Entropy Method}

Using the calculation process in Section 2.4.2, we can obtain the weights using the entropy method. First, Figure 2 shows that the weights given by the two methods are consistent overall. Both methods have five indicators whose values are greater than 0.06 , and forest coverage has the highest weight in both, despite quite large differences in net income per capita of farmers, forest coverage and plastic sheeting use. The remaining indicators have similar weights in two methods, and their differences are all less than 0.025 . For the discreteness degree of the weights, the entropy method yields a value of 0.006, whereas the EFAST method yields a value of 0.012. Thus, the results of the EFAST algorithm are more discrete, and the EFAST method can consequently identify the importance of indicators more effectively. Secondly, the indicators with top five weights given by the entropy method are as follows: forest coverage (0.070), net income per capita of farmers (0.069), fish consumption per capita (0.067), arable land output level (0.063) and agricultural disaster area (0.06). These results differ from the top five given by the EFAST method (besides the forest coverage indicator) because the EFAST method considers the coupling effects among indicators. Thus, the top five indicators based on the EFAST method are forest coverage, plastic sheeting use, chemical fertilizer application rate assuming $100 \%$ utilization, improvement rate of soil and water loss and arable land per capita. Although 
the relationships among the five indictors and the other indicators are uncertain, this interaction is sufficient to generate high sensitivity. The entropy method is based only on the discrete status of the data when assigning weights, thereby ignoring the coupling effect associated with other indicators. For the agricultural sustainable development indicator system, the slight change in indicators may result in different evaluation results. Hence, the influence of the interactions among indicators is non-ignorable for accurate evaluations.

\subsection{Comparison and Analysis of the Evaluation Results Produced by the EFAST and Entropy Methods}

According to the multi-index comprehensive evaluation model, the weights supplied by the entropy and EFAST methods can be used to calculate the comprehensive index of the agricultural sustainable development level in Henan province. The results are shown in Figure 3.

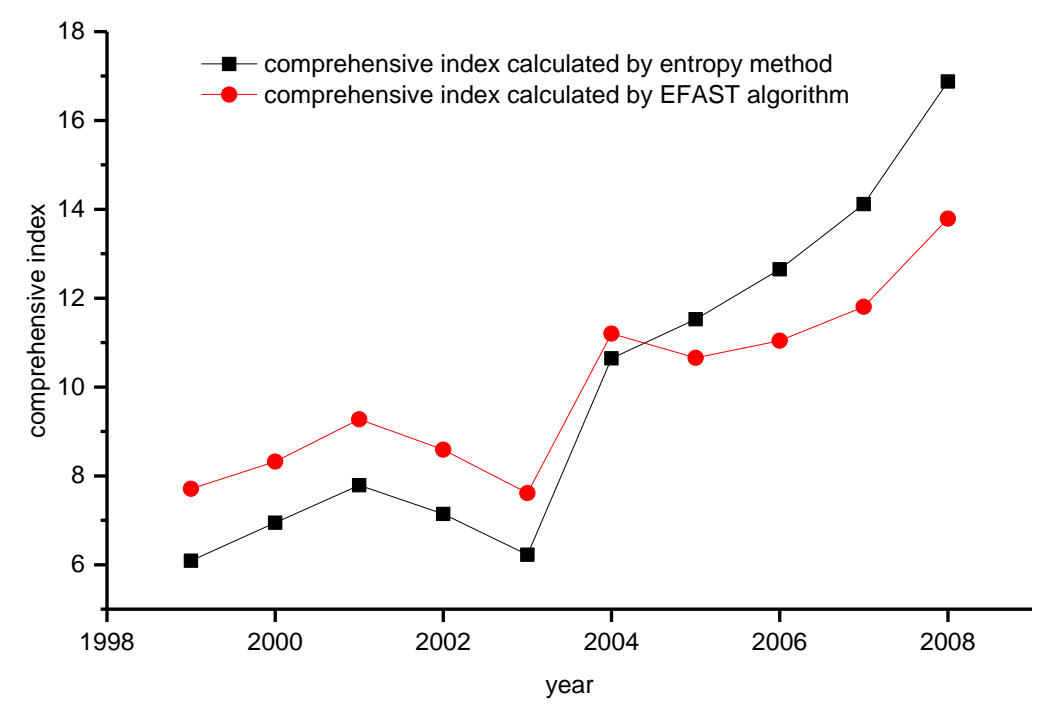

Figure 3. Agriculture development level of 1999-2008 in Henan province.

Figure 3 shows that the comprehensive index values calculated by the two methods both increase during 1999-2001 and decrease in 2002 and 2003. The decline in 2002 may due to the low prices of agricultural products. The Agricultural Producer's Price Index can reflect the volatility of prices over a certain period, and Figure 4a shows that the values of this index were low in 2002, with a value of only $92 \%$. To a certain extent, low agricultural prices will affect the enthusiasm of farmers for agricultural production. Additionally, the multiple cropping index and effective irrigation coefficient indicator values in 2002 were the lowest of the ten years. All of these factors produced a decline in the comprehensive index for this year. The decline in 2003 may have been caused by severe flooding disasters. According to the statistics, the agricultural disaster area in Henan province in 2003 reached 6.4338 million hectares (as shown in Figure 4b). The floods in 2003 produced the lowest 10-year values in positive indicators, such as arable land output level, grain share per capita and chemical fertilizer-dependent output assuming 100\% utilization, and the highest 10 -year values in the negative indicator agricultural energy consumption value. Serious agricultural losses created a low comprehensive index value in 2003. In the figure, the comprehensive index values based on the entropy method increase every year during 2003-2008. The comprehensive index values based on the EFAST method rise in 2003 and 2004 because the Chinese government introduced an agricultural tax relief policy and increased the agricultural subsidy, which were favorable policies that increased the enthusiasm of the farmers. The 2004-2005 period features a weak downward trend, but in this stage, the comprehensive index is still higher than in previous years. In Section 4.1, the forest coverage had the highest weight in both methods, which indicated that the evaluation result can be appreciably affected by the indicator. The value of this indicator decreased sharply from 2004-2005 (the forest 
coverage rate in this period declined from $19.8 \%$ down to $16.2 \%$ ). Considering it interacted with other indicators closely, this decrease can lead to an obvious downward trend, such as the meat share per capita was lower in 2005 than in 2004. Additionally, the improvement of negative indicators, such as the agricultural energy consumption index, was small. Besides, this period belonged to the agricultural production structure adjustment stage, and the comprehensive benefits of the structural adjustment of agricultural production still had not appeared yet. In conclusion, the downward trend during this stage reflected by the EFAST method is more realistic and reasonable than the entropy method's rising trend. In 2005-2008, the comprehensive index rises again. With the popularization and promotion of agricultural machinery and technology, relative to 2006, the indictors water use per $10^{4}$ yuan of agricultural output, agricultural energy consumption index and mechanical effective utilization factor improved significantly during the 2007-2008 period compared to 2006. The improvement in energy and resource use efficiency led to the increase in some positive indicators, such as grain share per capita, fish consumption per capita and net income per capita of farmers. Consequently, the comprehensive index rose from 2006-2008. This pattern also reflects the appearance of the comprehensive benefits of the structural adjustment of agricultural production.

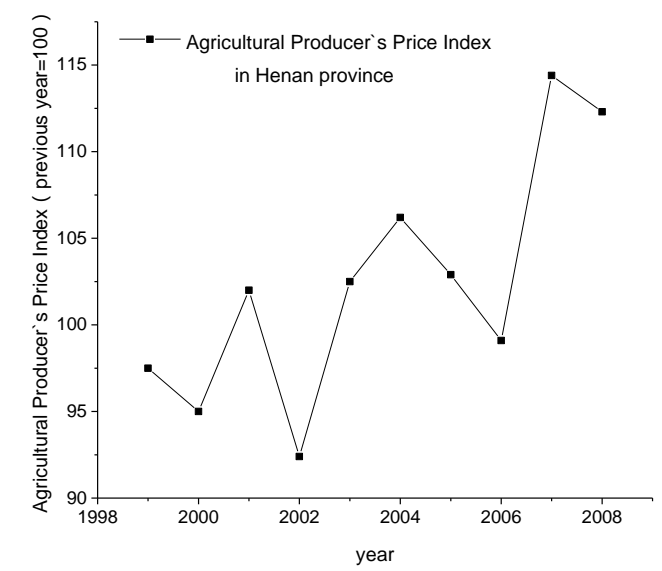

(a)

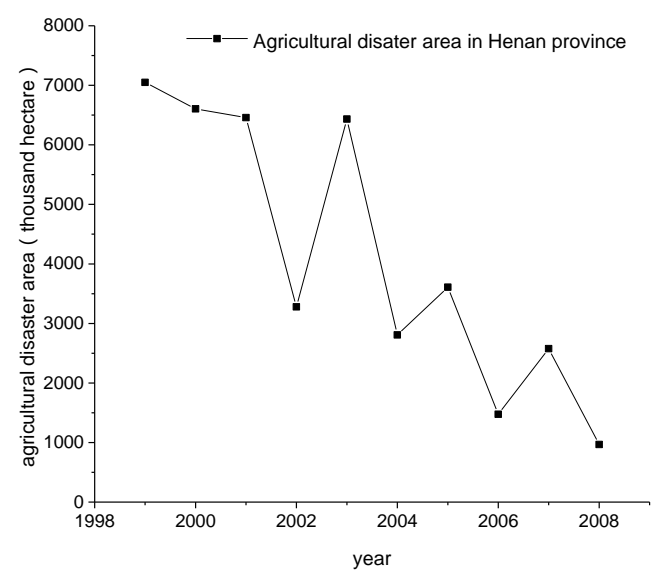

(b)

Figure 4. Agricultural producer's price index and agricultural disaster area in Henan during 1999-2008. (a) Agricultural producer's price index of 1999-2008 in Henan; (b) agricultural disaster area of 1999-2008 in Henan.

Although some differences exist among the weights of the two methods, the evaluation results exhibit nearly the same patterns. As the above analysis, both sets of results can be regarded as in line with reality, especially the EFAST method. The different trend in 2004-2005 reflects that the EFAST algorithm is more sensitive and can do better in capturing the slight changes in the SD level of agriculture in Henan province. The similarity demonstrates the feasibility of applying the EFAST algorithm in agricultural SD evaluations. Additionally, the subtle difference in EFAST reflects the actual SD level more truly. Therefore, from the above, we can figure out that the EFAST method can be a better choice in fixing indicator's weights.

\section{Conclusions}

This paper analyzes the determination of the weights of agricultural sustainable development indicators using the EFAST algorithm. The results of a comparison between the entropy method and EFAST method have demonstrated the feasibility and advantages of this new method. However, because the principle of the two methods varies, those two methods produce slightly different evaluation results. Based on our research, we have reached the following conclusions. 
The advantages of The EFAST method can be summarized as following. Firstly, the analysis of indicator weight by the EFAST algorithm is based on nearly ten thousand samples, and this method adds the coupling effects among the indicators through a quantitative calculation into consideration. Therefore, the EFAST method is more rational and comprehensive than the entropy method. Secondly, the weights assigned by the EFAST algorithm are more discrete than those of the entropy method, which reflects that the EFAST method can more efficiently separate the importance of the indicators. Lastly, but definitely not least, according to the results provided by the model, the comprehensive index calculated by the EFAST algorithm more effectively and accurately reflects the actual changes in agricultural sustainable development evaluations.

Some potential applications in the future research are listed as following: (1) the model we used in this research is just a simple linear model, and the difference between the MSI and TSI of each indicator is not significant. Therefore, the EFAST algorithm should be applied in more complicated models in the future. (2) Because the EFAST algorithm can efficiently reflect the importance of an indicator, there is potential to use it to simplify indicator systems and eliminate unimportant indicators.

Acknowledgments: This work was jointly supported by the National Natural Science Foundation of China (Grants 91625103 and 91425303) and the inter-disciplinary Innovation Team of the Chinese Academy of Sciences and the Science and Technology Service Network Initiative Project of the Chinese Academy of Sciences.

Author Contributions: Wenfei Luan analyzed the data and wrote the manuscript. Xin Li inspired the main idea. Ling Lu and Chunfeng Ma contributed to editing the manuscript and gave many suggestions. All authors contributed to the writing of the paper.

Conflicts of Interest: The authors declare no conflict of interest.

\section{References}

1. Lombardi, P.; Brandon, P.S. Evaluating sustainable development in the built environment. Environ. Plan. C Gov. Policy 2005, 24, 473-474.

2. Andriantiatsaholiniaina, L.A.; Kouikoglou, V.S.; Phillis, Y.A. Evaluating strategies for sustainable development: Fuzzy logic reasoning and sensitivity analysis. Ecol. Econ. 2004, 48, 149-172. [CrossRef]

3. Moran, D.D.; Wackernagel, M.; Kitzes, J.A.; Goldfinger, S.H.; Boutaud, A. Measuring sustainable development — nation by nation. Ecol. Econ. 2008, 64, 470-474. [CrossRef]

4. Si, H.; Bi, H.; Li, X.; Yang, C. Environmental evaluation for sustainable development of coal mining in qijiang, western china. Int. J. Coal Geol. 2010, 81, 163-168. [CrossRef]

5. Karger, C.R.; Hennings, W. Sustainability evaluation of decentralized electricity generation. Renew. Sustain. Energy Rev. 2009, 13, 583-593. [CrossRef]

6. Qiao, J.J. Application of improved entropy method in henan sustainable development evaluation. Resource. Science. 2004, 26, 113-119.

7. Diakoulaki, D.; Mavrotas, G.; Papayannakis, L. Determining objective weights in multiple criteria problems: The critic method. Comput. Oper. Res. 1995, 22, 763-770. [CrossRef]

8. Decancq, K.; Lugo, M.A. Weights in multidimensional indices of wellbeing: An overview. Econ. Rev. 2013, 32, 7-34. [CrossRef]

9. Singh, R.K.; Murty, H.R.; Gupta, S.K.; Dikshit, A.K. Development of composite sustainability performance index for steel industry. Ecol. Indic. 2007, 7, 565-588. [CrossRef]

10. Ma, J.; Fan, Z.-P.; Huang, L.-H. A subjective and objective integrated approach to determine attribute weights. Eur. J. Oper. Res. 1999, 112, 397-404. [CrossRef]

11. Wang, T.-C.; Lee, H.-D. Developing a fuzzy topsis approach based on subjective weights and objective weights. Expert Syst. Appl. 2009, 36, 8980-8985. [CrossRef]

12. Rao, R.V.; Patel, B.K. A subjective and objective integrated multiple attribute decision making method for material selection. Mater. Des. 2010, 31, 4738-4747. [CrossRef]

13. Saltelli, A.; Tarantola, S.; Chan, K.P.S. A quantitative model-independent method for global sensitivity analysis of model output. Technometrics 1999, 41,39-56. [CrossRef]

14. Palme, U.; Tillman, A.-M. Sustainable development indicators: How are they used in swedish water utilities? J. Clean. Prod. 2008, 16, 1346-1357. [CrossRef] 
15. Hardi, P. Measuring performance in sustainable development. Int. Conf. Environ. Pollut. Proc. 1996, 1-2, 70-76.

16. UNDP. Transforming Our World: The 2030 Agenda for Sustainable Development. Available online: https: //sustainabledevelopment.un.org/post2015/transformingourworld/ (accessed on 25 September 2015).

17. Mei, F.Q. China's Agricultural Sustainable Development and Comprehensive Productivity Research; Shandong Technology Press: Shandong, China, 1995.

18. Joung, C.B.; Carrell, J.; Sarkar, P.; Feng, S.C. Categorization of indicators for sustainable manufacturing. Ecol. Indic. 2013, 24, 148-157. [CrossRef]

19. Xin, L.; Hu, Z.Q. Evaluation of agriculture sustainable development level in China. J. Agr. Sci. Tech. (Beijing). 2015, 17, 135-142.

20. Stöglehner, G. Ecological footprint-A tool for assessing sustainable energy supplies. J. Clean. Prod. 2003, 11, 267-277. [CrossRef]

21. Cooper, W.W.; Seiford, L.M.; Zhu, J. (Eds.) Data envelopment analysis. In Handbook on Data Envelopment Analysis; Springer: Boston, MA, USA, 2004; pp. 1-39.

22. Spieksma, F.C.R. Multi index assignment problems: Complexity, approximation, applications. In Nonlinear Assignment Problems: Algorithms and Applications; Pardalos, P.M., Pitsoulis, L.S., Eds.; Springer: Boston, MA, USA, 2000; pp. 1-12.

23. Sobol, I.M. Sensitivity estimates for nonlinear mathematical model. Math. Model. Comput. Exp. 1993, $1,407-414$.

24. Ma, C.F.; Li, X.; Wang, S.G. A global sensitivity analysis of soil parameters associated with backscattering using the advanced integral equation model. IEEE Trans. Geosci. Remote Sens. 2015, 53, 5613-5623.

25. Morris, D.J.; Speirs, D.C.; Cameron, A.I.; Heath, M.R. Global sensitivity analysis of an end-to-end marine ecosystem model of the north sea: Factors affecting the biomass of fish and benthos. Ecol. Model. 2014, 273, 251-263. [CrossRef]

26. Cvetkovic, V.; Soltani, S.; Vigouroux, G. Global sensitivity analysis of groundwater transport. J. Hydrol. 2015, 531, 142-148. [CrossRef]

27. Wang, J.; Li, X.; Lu, L.; Fang, F. Parameter sensitivity analysis of crop growth models based on the extended fourier amplitude sensitivity test method. Environ. Model. Softw. 2013, 48, 171-182. [CrossRef]

28. Gan, Y.; Duan, Q.; Gong, W.; Tong, C.; Sun, Y.; Chu, W.; Ye, A.; Miao, C.; Di, Z. A comprehensive evaluation of various sensitivity analysis methods: A case study with a hydrological model. Environ. Model. Softw. 2014, 51, 269-285. [CrossRef]

29. Simlab. Simulation Laboratory for Uncertainty and Sensitivity Analysis. Available online: http://simlab.jrc. ec.europa.eu (18 February 2017).

30. Bhatta, B.; Saraswati, S.; Bandyopadhyay, D. Quantifying the degree-of-freedom, degree-of-sprawl, and degree-of-goodness of urban growth from remote sensing data. Appl. Geogr. 2010, 30, 96-111. [CrossRef]

31. Xianguang, G. Application of improved entropy method in evaluation of economic result. Syst. Eng.-Theory Pract. 1998, 18, 98-102.

32. Zou, Z.-H.; Yi, Y.; Sun, J.-N. Entropy method for determination of weight of evaluating indicators in fuzzy synthetic evaluation for water quality assessment. J. Environ. Sci. 2006, 18, 1020-1023. [CrossRef]

(C) 2017 by the authors. Licensee MDPI, Basel, Switzerland. This article is an open access article distributed under the terms and conditions of the Creative Commons Attribution (CC BY) license (http:/ / creativecommons.org/licenses/by/4.0/). 